\title{
Gyrate atrophy of the choroid and retina: ERG of the neural retina and the pigment epithelium
}

\author{
Christina Raitta, Synnöve Carlson, Kaarina Vannas-Sulonen
}

\begin{abstract}
The function of the neural retina and the pigment epithelium in $\mathbf{1 0}$ patients with gyrate atrophy was examined by the conventional alternating current electroretinogram and by direct current electroretinography to study the $c$-wave. The a- and b-wave responses were subnormal in all patients and the ERG was undetectable in patients with an advanced stage of the disease. The c-wave was recordable by the DC ERG from three patients with a less advanced stage of the disease. In one patient the c-wave could be recorded only from the other eye but the a- and b-wave responses were recordable in both his eyes.
\end{abstract}

Gyrate atrophy of the choroid and retina (GA) is a rare form of hereditary retinal dystrophy accompanied by a defect in ornithine metabolism. ' The clinical opthalmological findings in GA include myopia, cataract, and chorioretinal degeneration. The metabolic defect presents as hyperornithinaemia, ornithuria, and deficiency of ornithine aminotransferase activity. ${ }^{2}$ The human gene responsible for GA has been localised to chromosome $10 .^{3}$

The full-field ERG has been shown to be reduced in amplitude at an early stage in GA patients, ${ }^{4}$ and no normal ERG recordings have been reported in them..$^{5}$ Ophthalmoscopic and fluorescein angiographic findings of young patients suggest that the retinal pigment epithelium is affected early in the course of the disease. $^{46}$ One histological study on animals indicates that the primary changes in GA are located in the pigment epithelium. ${ }^{7}$

We studied $10 \mathrm{GA}$ patients with a full-field flash ERG to establish the degree and cell level of the disturbance in the function of the neural retina. The c-wave of the ERG, which originates in the pigment epithelium, ${ }^{9}{ }^{10}$ was recorded by a direct current (DC) method. ${ }^{8}$ The purpose of this study is to evaluate the function of the pigment epithelium as revealed by the ERG $c$-wave and to correlate these findings with the $a-$ and $b$-waves of the conventional alternating current (AC) ERG in GA patients.

\section{Material and methods}

Ten GA patients, five females and five males, aged 7-46 years (mean 27 years) were studied. The results were compared with the recordings of eight normal subjects (aged 20-46 years, mean 31 years). The GA diagnosis was based on ophthalmoscopic findings, hyperornithinaemia, ornithuria, and established deficiency of the ornithine aminotransferase enzyme." The latest plasma ornithine level of the patients was at 205-
TABLE I Age and sex distribution, visual acuity, and stage of disease and cataract of the $G A$ patients

\begin{tabular}{|c|c|c|c|c|c|c|c|}
\hline \multirow[b]{2}{*}{ Case } & \multirow[b]{2}{*}{ Age } & \multirow[b]{2}{*}{ Sex } & \multirow[b]{2}{*}{$G A$ stage } & \multicolumn{2}{|c|}{ Vision } & \multicolumn{2}{|c|}{ Cataract } \\
\hline & & & & $O D$ & OS & $O D$ & $O S$ \\
\hline 1 & 7 & F & I & 0.6 & $0 \cdot 7$ & & - \\
\hline 2 & 12 & $\mathbf{F}$ & I & $0 \cdot 8$ & $0 \cdot 7$ & Centr & al opacity \\
\hline 3 & 14 & $\mathbf{F}$ & I-II & $0 \cdot 7$ & 0.4 & Small & opacity \\
\hline 4 & 16 & M & I-II & 0.5 & $0 \cdot 2$ & - & - \\
\hline 5 & 21 & M & I & 0.8 & 0.6 & & - \\
\hline 6 & 36 & M & III & $0 \cdot 2$ & 0.2 & Apha & \\
\hline 7 & 37 & M & IV & 0.25 & $0 \cdot 3$ & Apha & \\
\hline 8 & 38 & $\mathrm{~F}$ & II-III & $0 \cdot 2$ & $0 \cdot 3$ & Apha & \\
\hline 9 & 41 & $F$ & IV & $0 \cdot 2$ & $0 \cdot 2$ & Apha & kia \\
\hline 10 & 46 & $\mathbf{M}$ & II & 0.6 & 0.4 & Poste & rior opacity \\
\hline
\end{tabular}

Grading ${ }^{16}:$ Stage I: Round, separate, or fused atrophic areas in the midperiphery of the fundus. Stage II: Fused atrophic areas approaching the posterior pole. Stage III: A large degenerative area round the disc. Stage IV: all the posterior pole except the macula are atrophic.

$1300 \mu \mathrm{mol} / \mathrm{l}$ (mean $733 \mu \mathrm{mol} / \mathrm{l}$, normal $<70$ $\mu \mathrm{mol} / \mathrm{l})$. The visual functions of the patients are summarised in Table I.

The subjects were dark adapted for 30 minutes before the ERG recording. The pupils were dilated with $0.5 \%$ tropicamide (Oftan Tropicamide) which produced a dilatation of 7-8 $\mathrm{mm}$. The other eye was covered. The recordings were performed with the subjects supine. Both eyes were examined in the same session, the right eye first. There was an additional 15 min dark adaptation between the recordings of the two eyes.

A photostimulator (Grass PS22) with a xenon flash lamp was used. The duration of the flash was $10 \mu \mathrm{s}$ and the maximum intensity $3.38 \mu \mathrm{J} /$ $\mathrm{cm}^{2}$ at the eye level (measured with Model 350 Linear/Log Optometer with a photometric filter 21043, United Detector Technology). The stimulus light was attenuated with neutral density filters (Kodak). To obtain a near uniform illumination of the retina a full-field stimulator was used (LKC Systems Inc), which reduces the problems related to uncertain fixation. ${ }^{12} 13$

The recordings were performed with a disposable corneal wick electrode described by Sieving et $a l^{14}$ and slightly modified by us. The recording method is described in detail elsewhere ${ }^{8}$ As no lid speculum was used, the subject was able to blink. The electrode was placed on the surface of the topically anaesthetised eye $(0.4 \%$ oxybuprocaine hydrochloride, Oftan Obucain), where it settled above the margin of the lower lid. The electrode is well tolerated, and occasional blinking keeps it moist.

Beckmann's Ag-AgCl disk electrodes were used as ground (on the forehead) and reference (on the ipsilateral temple) electrodes. The preparations for the recording were performed in a darkened room with the help of a dim red slitlamp (luminance $2 \mathrm{~cd} / \mathrm{m}^{2}$ ). The corneal potentials were amplified (amplification 1000) with an 
TABLE II The $a$-and $b$-wave implicit times and amplitudes of the $G A$ patients and normal subjects

\begin{tabular}{|c|c|c|c|c|c|c|c|c|}
\hline & \multicolumn{3}{|c|}{ Patients } & \multicolumn{3}{|c|}{ Controls } & \multicolumn{2}{|c|}{ Student's t test } \\
\hline & $n$ & $\begin{array}{l}\text { Mean } \\
(m s)\end{array}$ & $S D$ & $n$ & $\begin{array}{l}\text { Mean } \\
\text { (ms) }\end{array}$ & $S D$ & $t$ & $p$ \\
\hline $\begin{array}{l}\text { IMPLICIT TIME } \\
\text { a-Wave } \\
\text { KW } 47 \mathrm{~B}+\mathrm{ND} 0.6 \\
\text { KW } 25 \\
\text { ND } 1 \\
\text { Bgr, KW } 25 \\
\text { Bgr, ND } 1\end{array}$ & $\begin{array}{l}11 \\
11 \\
11 \\
10 \\
10\end{array}$ & $\begin{array}{l}29.3 \\
17.9 \\
19.9 \\
15.9 \\
15.9\end{array}$ & $\begin{array}{l}4 \cdot 1 \\
2 \cdot 8 \\
4 \cdot 4 \\
2 \cdot 6 \\
2 \cdot 0\end{array}$ & $\begin{array}{l}11 \\
11 \\
11 \\
11 \\
11\end{array}$ & $\begin{array}{l}27 \cdot 7 \\
16 \cdot 3 \\
17 \cdot 0 \\
14 \cdot 0 \\
14 \cdot 6\end{array}$ & $\begin{array}{l}0.72 \\
0.47 \\
0.44 \\
1.13 \\
0.98\end{array}$ & $\begin{array}{l}1 \cdot 27 \\
1.86 \\
2 \cdot 18 \\
2 \cdot 23 \\
1.90\end{array}$ & $\begin{array}{l}- \\
\overline{-} \\
<0.05 \\
<0.05 \\
-\end{array}$ \\
\hline \multirow[t]{3}{*}{$\begin{array}{l}b \text {-Wave } \\
\text { KW 47B+ND } 2 \\
\text { KW 47B + ND 0.6 } \\
\text { KW 25 } \\
\text { ND 1 } \\
\text { Bgr, KW } 25 \\
\text { Bgr, ND 1 } \\
\text { Flicker }\end{array}$} & $\begin{array}{l}10 \\
11 \\
11 \\
11 \\
11 \\
11 \\
11\end{array}$ & $\begin{array}{l}85 \cdot 5 \\
54 \cdot 6 \\
51 \cdot 6 \\
45 \cdot 5 \\
31 \cdot 8 \\
29 \cdot 7 \\
32 \cdot 8\end{array}$ & $\begin{array}{l}9 \cdot 9 \\
6 \cdot 6 \\
3 \cdot 9 \\
7 \cdot 3 \\
3 \cdot 6 \\
2.9 \\
1.6\end{array}$ & $\begin{array}{l}11 \\
11 \\
11 \\
11 \\
11 \\
11 \\
11\end{array}$ & $\begin{array}{l}81 \cdot 9 \\
51 \cdot 1 \\
52 \cdot 7 \\
43 \cdot 0 \\
28 \cdot 2 \\
27 \cdot 3 \\
29 \cdot 9\end{array}$ & $\begin{array}{l}4 \cdot 1 \\
2 \cdot 1 \\
1 \cdot 5 \\
3 \cdot 1 \\
0 \cdot 45 \\
0 \cdot 72 \\
1 \cdot 27\end{array}$ & $\begin{array}{l}1 \cdot 10 \\
1 \cdot 48 \\
0 \cdot 87 \\
1 \cdot 05 \\
3 \cdot 29 \\
2 \cdot 64 \\
4 \cdot 71\end{array}$ & $\begin{array}{l}- \\
- \\
- \\
- \\
<0.01 \\
<0.05 \\
<0.001\end{array}$ \\
\hline & & & & & & & \multicolumn{2}{|c|}{ Wilcoxon test } \\
\hline & $n$ & $\begin{array}{l}\text { Med. } \\
(\mu V)\end{array}$ & $\begin{array}{l}\text { Range } \\
\text { min/max }\end{array}$ & $n$ & $\begin{array}{l}\text { Med. } \\
(\mu V)\end{array}$ & $\begin{array}{l}\text { Range } \\
\text { min/max }\end{array}$ & $u$ & $p$ \\
\hline $\begin{array}{l}\text { AMPLITUDE } \\
a \text {-Wave } \\
\text { KW 47B + ND 0.6 } \\
\text { KW } 25 \\
\text { ND } 1 \\
\text { Bgr, KW } 25 \\
\text { Bgr, ND 1 }\end{array}$ & $\begin{array}{l}11 \\
11 \\
11 \\
10 \\
10\end{array}$ & $\begin{array}{r}3 \cdot 5 \\
17 \cdot 5 \\
38 \cdot 5 \\
7 \cdot 9 \\
9 \cdot 4\end{array}$ & $\begin{array}{l}3 \cdot 5 / 42 \\
3 \cdot 5 / 49 \\
3 \cdot 5 / 119 \\
3 \cdot 5 / 13 \\
1 \cdot 8 / 28\end{array}$ & $\begin{array}{l}11 \\
11 \\
11 \\
11 \\
11\end{array}$ & $\begin{array}{l}63 \\
45 \cdot 5 \\
136 \\
17 \cdot 5 \\
21\end{array}$ & $\begin{array}{l}46 / 101 \\
32 / 81 \\
88 / 220 \\
14 / 32 \\
15 / 35\end{array}$ & $\begin{array}{l}3.94 \\
3 \cdot 84 \\
3.74 \\
3 \cdot 83 \\
3 \cdot 17\end{array}$ & $\begin{array}{l}<0.001 \\
<0.001 \\
<0.001 \\
<0.001 \\
<0.001\end{array}$ \\
\hline $\begin{array}{l}b \text {-Wave } \\
\text { KW 47B+ND } 2 \\
\text { KW 47B+ND 0.6 } \\
\text { KW 25 } \\
\text { ND 1 } \\
\text { Bgr, KW } 25 \\
\text { Bgr, ND 1 } \\
\text { Flicker }\end{array}$ & $\begin{array}{l}10 \\
11 \\
11 \\
11 \\
11 \\
11 \\
11\end{array}$ & $\begin{array}{l}40 \cdot 2 \\
49 \cdot 0 \\
45 \cdot 5 \\
38 \cdot 5 \\
24 \cdot 5 \\
32 \cdot 5 \\
24 \cdot 5\end{array}$ & $\begin{array}{l}21 / 74 \\
28 / 154 \\
18 / 175 \\
18 / 108 \\
14 / 30 \\
6 / 49 \\
7 / 61\end{array}$ & $\begin{array}{l}11 \\
11 \\
11 \\
11 \\
11 \\
11 \\
11\end{array}$ & $\begin{array}{r}157 \cdot 0 \\
213 \cdot 0 \\
248 \cdot 0 \\
157 \cdot 0 \\
71 \cdot 7 \\
96 \cdot 2 \\
59 \cdot 5\end{array}$ & $\begin{array}{r}95 / 220 \\
147 / 329 \\
147 / 413 \\
84 / 325 \\
44 / 129 \\
51 / 140 \\
25 / 110\end{array}$ & $\begin{array}{l}3.83 \\
3.87 \\
3.84 \\
3.81 \\
3.94 \\
3.94 \\
2.99\end{array}$ & $\begin{array}{l}<0.001 \\
<0.001 \\
<0.001 \\
<0.001 \\
<0.001 \\
<0.001 \\
<0.01\end{array}$ \\
\hline
\end{tabular}

$\mathrm{KW}=$ Kodak Wratten $. \mathrm{ND}=$ neutral density $. \mathrm{Bgr}=$ background. $\mathrm{n}=$ Number of eyes.

AC/DC ERG amplifier (Biotronics, PO Box 29, SF-02421 Jorvas, Finland) and filtered (AC recording; low pass frequency $400 \mathrm{~Hz}$, DC recording; low pass frequency $30 \mathrm{~Hz}$ ). The recorded potentials were displayed on a digital oscilloscope (Gould 1425), which also provided the possibility for signal averaging. The implicit times (measured from the onset of the stimulus to the peak of the waves) and the amplitudes (measured from the baseline to the peak of the waves) were measured with a cursor. For the a-wave the earliest negative peak was measured. The waveforms were drawn from the oscilloscope with a pen recorder (Gould LS270) with a slow drawing speed ( $20 \mathrm{~s} /$ trace).

In the first recording session both eyes were studied for rod and cone mediated responses. Dark-adapted responses were elicited with the following test stimuli in the absence of a background illumination:

(1) Blue flash $\left(\mathrm{KW} 47 \mathrm{~B}\right.$, intensity $0.247 \times 10^{-1}$ $\mu \mathrm{J} / \mathrm{cm}^{2}$ ) attenuated with neutral density filters to determine the b-wave threshold. (2) Blue flash (KW47B with 2.0 log units attenuation, intensity $\left.0 \cdot 195 \times 10^{-3} \mu \mathrm{J} / \mathrm{cm}^{2}\right)$ to elicit a rod mediated response. (3) Blue flash (KW47B with $0.6 \mathrm{log}$ unit attenuation, intensity $0.140 \times 10^{-1}$ $\left.\mu \mathrm{J} / \mathrm{cm}^{2}\right)$ to elicit a rod mediated response. (4) Red flash (KW25, intensity $0.459 \mu \mathrm{J} / \mathrm{cm}^{2}$ ) to elicit a mixed cone and rod mediated response; the red stimulus and the previous blue stimulus (KW47B with 0.6 log unit attenuation) were matched subjectively to be equally strong stimuli for the rod system. ${ }^{15}(5)$ White flash with $1.0 \mathrm{log}$ unit attenuation (intensity $0.394 \mu \mathrm{J} / \mathrm{cm}^{2}$ ) to elicit a mixed cone and rod mediated response.

With a white background illumination in the globe (luminance $28 \mathrm{~cd} / \mathrm{m}^{2}$ ) the following test stimuli were presented to elicit cone mediated responses:

(1) Blue flash (KW47B with $0.6 \mathrm{log}$ unit attenuation). With this stimulus no response was recordable in normal subjects, so that the same stimulus in the dark-adapted conditions elicited the response mainly from the rod system. This control test was performed only in normal subjects. (2) Red flash (KW25). (3) White flash with $1.0 \log$ unit attenuation. (4) White $30 \mathrm{~Hz}$ flicker (intensity of the white flash $3.38 \mu \mathrm{J} / \mathrm{cm}^{2}$ ). The c-wave was recorded in a separate session.

The patient was prepared for the recording as described above. A DC recording method was used which enabled the recording of the slow c-wave. A small red fixation light was lit inside the globe to help the patient maintain fixation for several seconds. The subjects were instructed to avoid movement and blinking during several seconds after the stimulus. The stimulus was a white flash with $1.0 \mathrm{log}$ unit attenuation (intensity $0.394 \mu \mathrm{J} / \mathrm{cm}^{2}$ ). A prestimulus time of 0.96 second was provided for the recordings by the recording system, and the response to each stimulus was recorded for 10 seconds. No signal averaging was used to avoid contamination of the recordings by occasional traces containing eye blinks or eye movements. Several single responses were recorded. All recordings were performed in the morning.

\section{Results}

AC ERG was performed in both eyes of eight patients (cases $1-5,7,9$, and 10). In two patients (cases 6 and 8) only one eye was studied because their other eye had recently been operated on for cataract. When a- and b-waves were undetectable, no c-wave recording was attempted (cases 6-9). Thus the DC ERG was performed on six patients (cases $1-5$ and 10).

The AC ERG was isoelectric in both eyes of two patients (cases 7 and 9), in the recorded eye of cases 6 and 8 , and in one eye of case 3 . The b-wave threshold was raised in all patients with measurable responses.

The results of the a- and b-wave recordings of those GA patients whose ERG was not isoelectric are listed in Table II together with the results of the normal recordings. The implicit times of the a- and b-waves were slightly delayed in GA patients in comparison with normal subjects, but the difference was statistically significant only for the cone mediated responses (statistical analysis was by Student's $t$ test for independent samples) (Table II). The implicit time of the a-wave was significantly delayed in GA patients in comparison with normal subjects also in one test for mixed rod and cone mediated response (white flash without background illumination). In all recordings of the GA patients the a- and b-wave amplitudes were reduced. The difference in results between the GA patients and normal subjects was also statistically significant (nonparametric Wilcoxon test for independent samples) (Table II). Figure 1 shows an example of the normal recording. The responses of three patients (cases 2, 4, and 8) are illustrated in Figure 2A, B, C. 
Figure 1: Normal AC ERG recording. From top to bottom: $b$-wave threshold (blue stimulus, $K W 47 B$, $\left.10^{+} \mathrm{\mu f} / \mathrm{cm}^{2}\right)$; rod mediated response (KW $47 B, N D 2)$; rod mediated response (KW 47B, ND 0.6); mixed rod and cone mediated response (red stimulus, KW25); mixed rod and cone mediated response (white stimulus, $N D$ 1); no response illumination, $28 \mathrm{~cd} / \mathrm{m}^{2}$, and blue stimulus, $K W 47 B$, ND 0.6); cone mediated response (white background illumination and red stimulus, $K W 25$ ), cone mediated response (white background illumination and white stimulis, ND 1); cone mediated response (white background illumination, $30 \mathrm{~Hz}$ white ficker, flash with no attenuation). Dashed line indicates the occurrence of the stimulus (duration 10 $\mu s)$. Each recording is the average of four single $W=$ white, bgr $=$ background illumination. ND $3 \cdot 3$, intensity $0 \cdot 118 \times$ (see text) (white background responses. $B=$ blue, $R=$ red

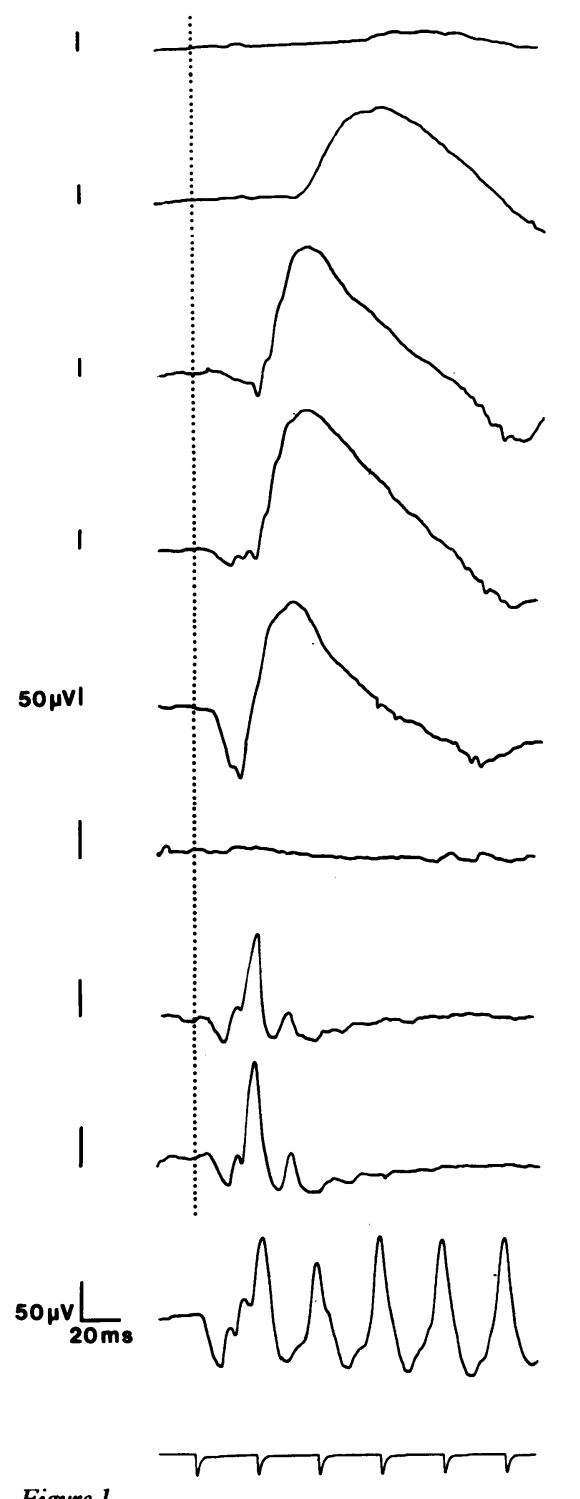

Figure 1

Figure 2: Flash ERG of three patients. A: A 16-yearold male (case 4), right eye. B: A 12-year-old girl (case 2), right eye. C: A 38-yearold woman (case 8). The stimuli from top to bottom: (1) blue ( $K W 47 B, N D 2)$; (2) blue (KW 47B,ND 0.6); (3) red (KW 25); (4) white (ND 1); (5) white background illumination $(28$ $\left.c d / m^{2}\right)$, red flash ( $\left.K W 25\right)$; (6) white background illumination, white flash (ND 1); (7) white background illumination, 30 $\mathrm{Hz}$ white flicker, flash with no attenuation. Each recording is the average of four single responses. $B=$ blue, $R=$ red, $W=$ white, $b g r=b a c k g r o u n d$ illumination.
B

B

B

$\mathbf{R}$

w

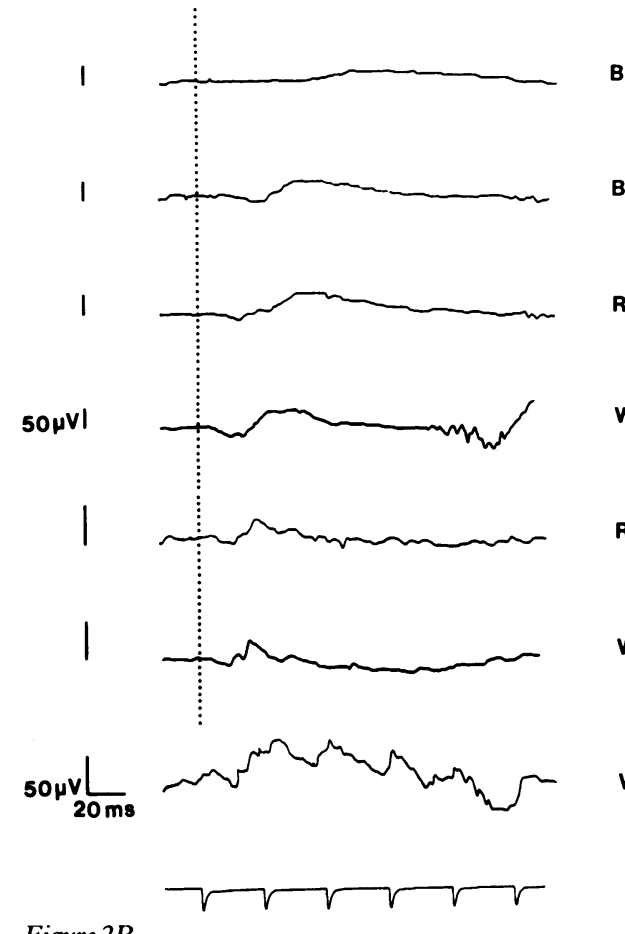

w

R,bgr

w, bgr

w,bgr

Figure 2B

R,bgr

W,bgr

w, bgr

The c-wave was recorded in six patients (cases 1-5 and 10). In one patient (case 1) the DC recording failed. This 7 -year-old girl could not avoid moving the eyes during the recording. In one patient (case 2) the c-wave was recordable in both eyes (Fig 3). She was the second youngest (12 years) of the patients in this study. The clinical ophthalmological findings of her eyes corresponded to stage $I$ in the grading described by Takki ${ }^{16}$ (Fig 4$)$. In the 16-year-old male (case 4) the c-wave was recordable from the right eye but not from the left (Fig 3). This finding was verified by repeating the recordings the following day. The clinical ophthalmological findings
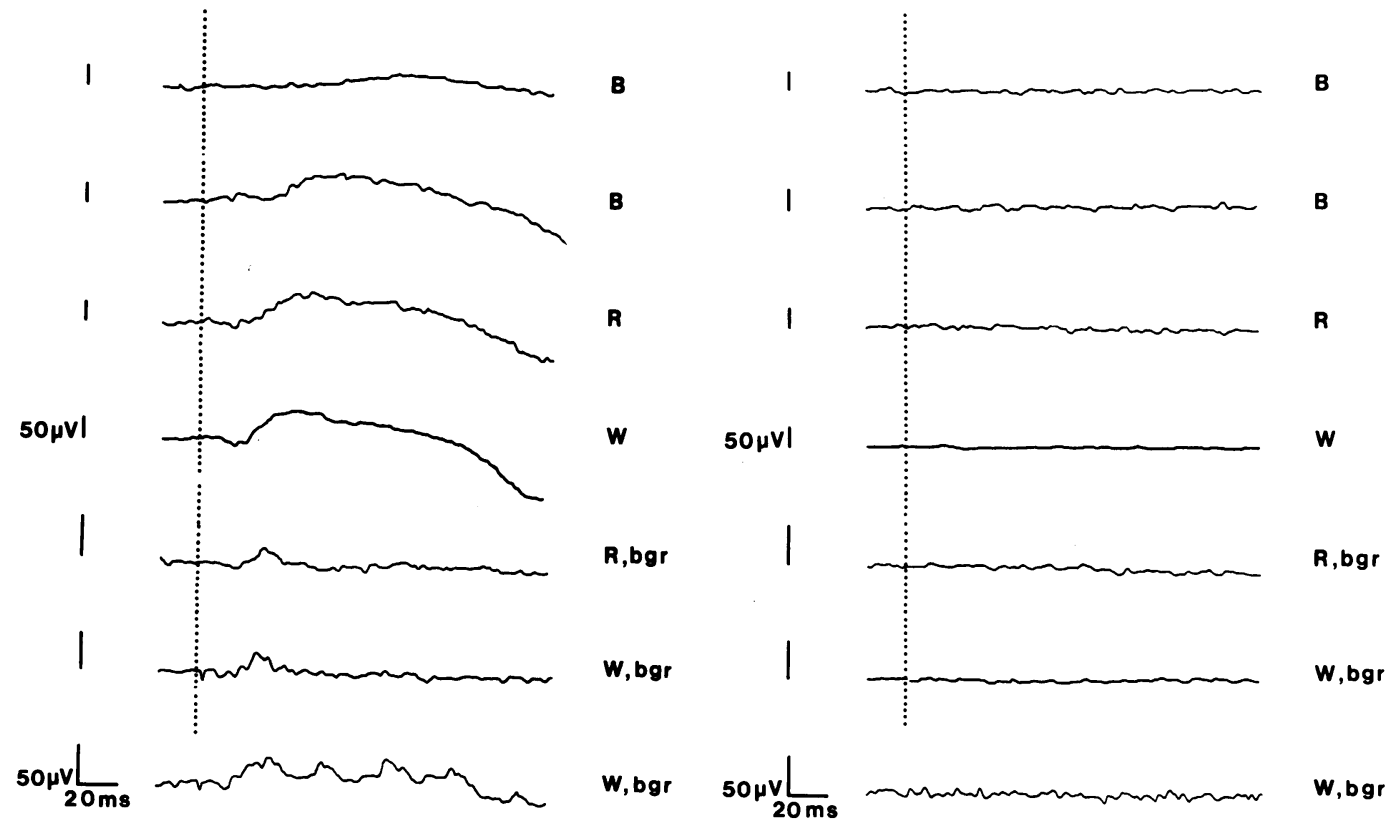

Figure 2C

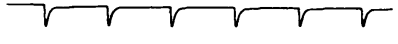

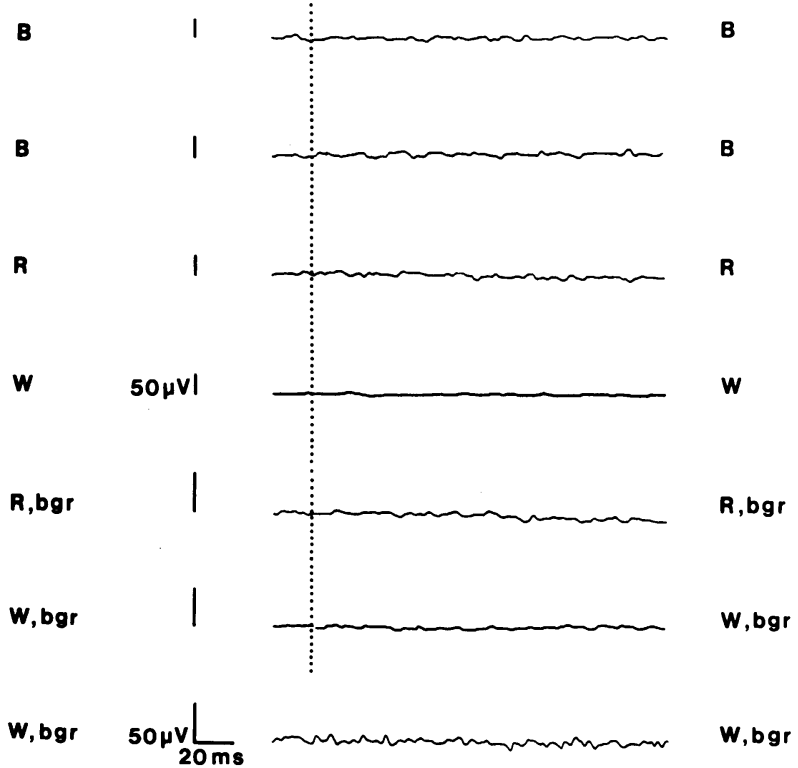

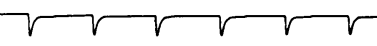



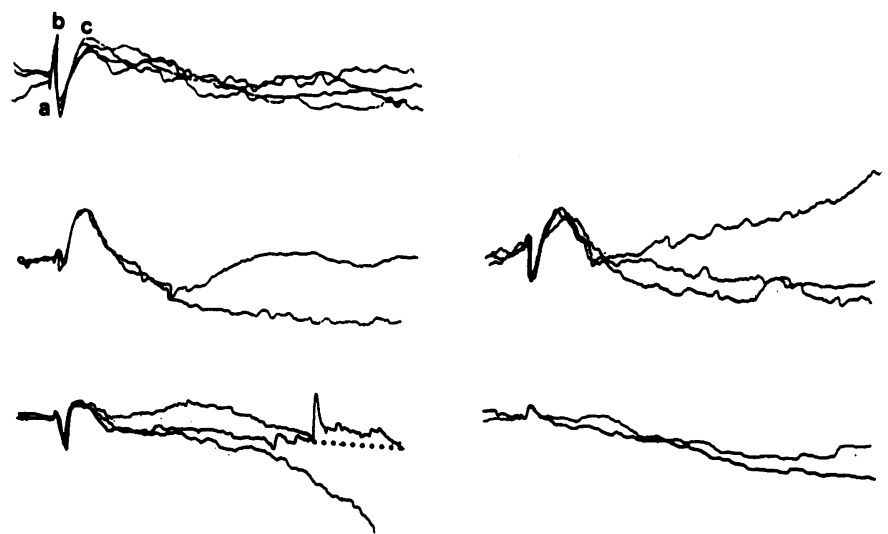

$100 \mu v L_{18}$
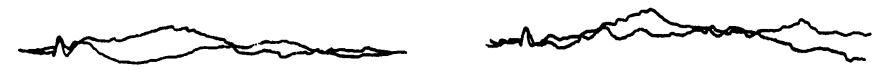

Figure 3: Examples of the c-wave recordings. Top: Normal c-wave recording. Second: Case 2. $C$-waves were recordable in both eyes. Third: Case $4 . C$-wave was recordable in the right eye (left) but not in the left eye (right). Bottom: Case 10. A small positive deflection at a latency characteristic of the c-wave in the recordings from both eyes. The stimulus, a white flash with 1.0 $\log$ unit attenuation (duration $10 \mu \mathrm{s}$ ), was presented just before the occurrence of the a-and $b$-waves with a latency of $0.96 \mathrm{~s}$ from the beginning of the recording. Two to four responses are superimposed.

TABLE III Implicit time and amplitude of the c-wave in $G A$ patients and in normal persons

\begin{tabular}{|c|c|c|c|}
\hline & & Implicit time (s) & Amplitude $(\mu V)$ \\
\hline Case 2 & $\begin{array}{l}\text { OD } \\
\text { OS }\end{array}$ & $\begin{array}{l}0.79 \\
0.85\end{array}$ & 127 \\
\hline Case 4 & OD & 0.79 & $\begin{array}{r}124 \\
98\end{array}$ \\
\hline & OS & - & - \\
\hline Case 10 & OD & $\begin{array}{l}0.76 \\
0.80\end{array}$ & 10 \\
\hline Normal & $n=9$ & $\begin{array}{ll}0.90 & 0.08 \\
(\text { Mean) } & (\mathrm{SD})\end{array}$ & $\begin{array}{l}147 \quad 80 \\
\text { (Mean) }\end{array}$ \\
\hline
\end{tabular}

of his eyes corresponded to stage I-II (Fig 5). A small positive deflection with an implicit time characteristic of the c-wave, was recorded from case 10 (stage II). In the other two patients (cases 3 and 5) no c-wave was recordable from either eye. The results of the c-wave recordings of the GA patients are listed in Table III together with the normal values.

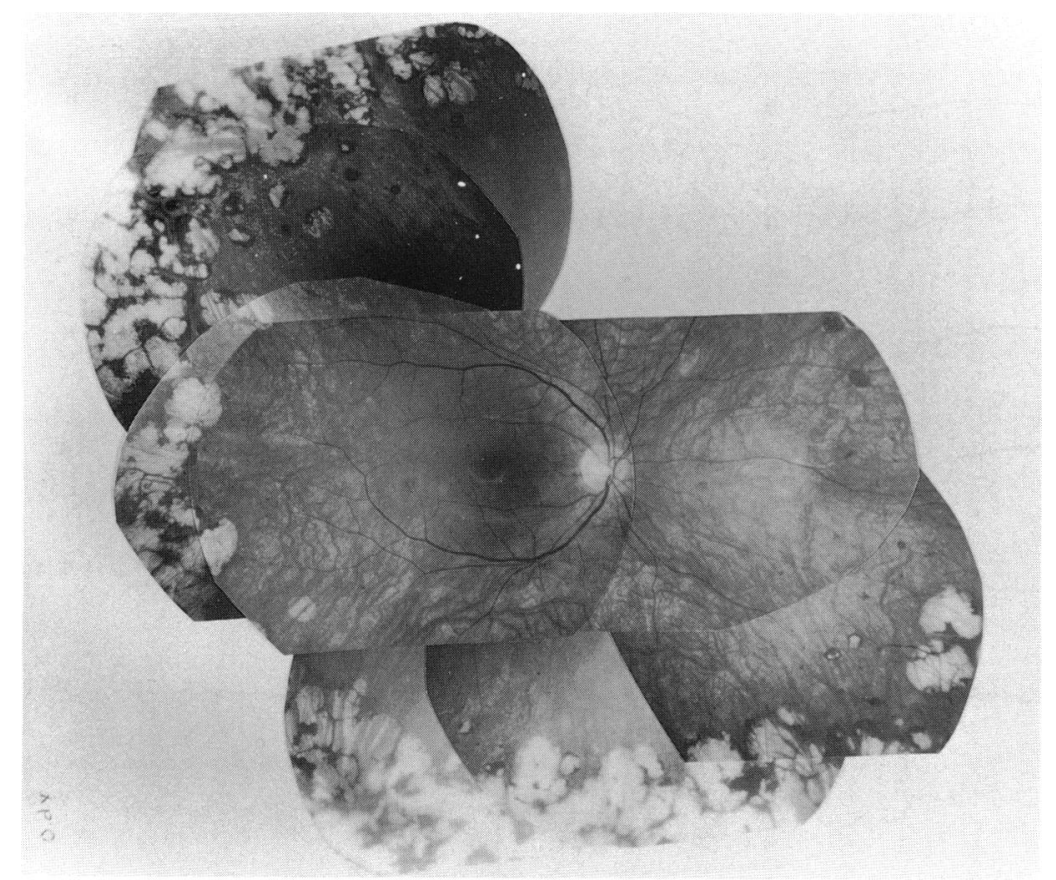

Figure 4: Composite photograph of the right eye at stage 1 of a patient aged 12 years (case 2). Mainly separate peripheral chorioretinal atrophic patches. Normal optic disc, macula, and retinal vessels.

\section{Discussion}

The first detailed ophthalmological description of the characteristics of GA appeared in $1974 .^{16}$ Since then several reports on the electrophysiological findings in GA have recorded that the ERG is severely affected and may become undetectable at an early stage of the disease. ${ }^{+617-20}$ Typical for the disease is that its progress is variable and does not correlate with the age of the patients. ${ }^{121}$

In the present study the ERG was undetectable in patients whose clinical ophthalmological findings corresponded to GA stages II-IV (cases 3 and 6-9). The stage of the disease was less advanced in those patients who still had measurable responses in their ERG (cases 1-5 and 10). Both rod and cone mediated a- and b-wave amplitudes were decreased in the ERG of these patients, indicating that the rod and cone systems are affected jointly in GA. Of the two young patients described by Berson et al ${ }^{18}$ one had a markedly depressed ERG with rod responses more reduced than cone responses. Kaiser-Kupfer $e t a l^{4}$ on the other hand did not report a difference in the degree of impairment of the two systems.

The c-wave was recordable in both eyes of the 12-year-old patient (case 2, stage I) of this study. In her AC ERG there was already a marked reduction in both cone and rod mediated responses. Of particular interest is case 4 (the 16year-old male), in whose right eye the c-wave was still recordable but not in the left eye. The rod and cone mediated responses, however, were recordable in both eyes. In the DC ERG of case 10 (a 46-year-old male) a small positive deflection occurred in both eyes at a latency characteristic of the c-wave. The clinical picture of case 10 (stage II) indicates that his disease has progressed slowly and is an example of the heterogeneity of GA. The DC ERG findings of this study indicate that the c-wave can be recorded only at an early stage of the disease.

Since Noell's observation that the c-wave disappears after the pigment epithelium is selectively destroyed" several studies have supported the idea that the c-wave is in large part elicited by the pigment epithelium. ${ }^{102}$ When retina is illuminated, there is a decrease in the extracellular levels of $\mathrm{K}^{+}$around the photoreceptors which gives rise to a hyperpolarisation of the apical membrane and to a less extent of the basal membrane of the pigment epithelium. ${ }^{23}$

The retinal pigment epithelium maintains the photoreceptor cell homoeostasis. The light sensitive disc membranes in the outer segments of the photoreceptor cells are renewed normally throughout life. This process involves multiple steps, ${ }^{24}$ and a defect in one step may disturb the renewal mechanism and lead to cell abnormalities or cell death. The disappearance of the c-wave at an early stage of the disease is an indication of the disturbed function of the pigment epithelium.

To our knowledge this is the first time that any electrophysiological evidence of the function of the pigment epithelium in GA has been presented. The c-wave was detectable only in the early stages of the disease. In all patients with recordable c-waves the photoreceptor responses were subnormal. With clinical ERG it is not 


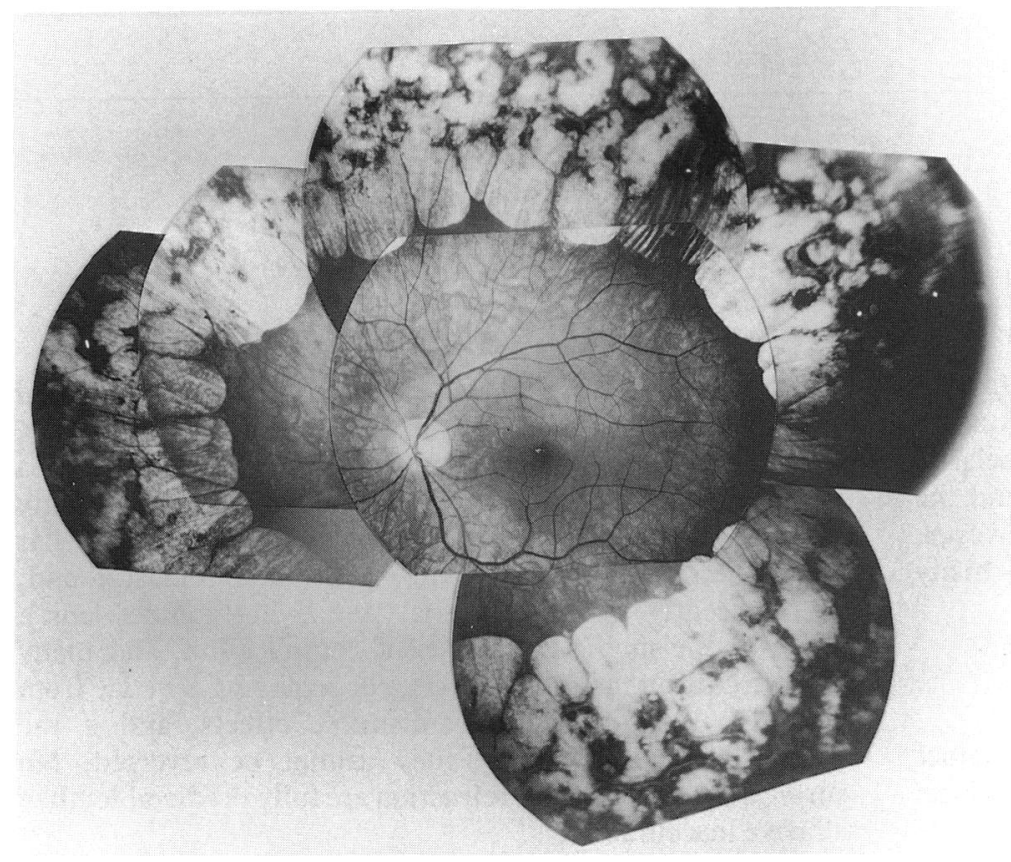

Figure 5: Composite photograph of the left eye at stages 1-2 of a patient aged 16 years (case 4). Sharply demarcated confluent atrophic patches of garland shaped configuration. Normal optic disc and retinal vessels. Small pigmentary defect parafoveally in the left eye.

possible to determine whether the pigment epithelium is affected earlier in GA than the neural retina. However, in case 4 the absence of the c-wave in the other eye, in which a- and $b$-waves were still recordable, may be an indication that the functional disturbance originates in the pigment epithelium.

We thank Mrs Pirjo Cleve for technical assistance. This study was supported by a grant from the Academy of Finland and from The Eye Foundation.

1 Simell O, Takki K. Raised plasma-ornithine and gyrate atrophy of the choroid and retina. Lancet 1973; i: 1031-3.

2 Sengers RCA, Trijbels JMF, Brussaart JH, Deutman AF Gyrate atrophy of the choroid and retina and ornithineketoacid aminotransferase deficiency. Pediatr Res 1976; 10 894.
3 O'Donnell JJ, Vannas-Sulonen K, Shows T, Cox D. Ornithine aminotransferase maps to human chromosome 10 and mouse chromosome 7. Cytogenet Cell Genet 1985; 40: 716A.

4 Kaiser-Kupfer MI, Ludvig IH, de Monasterio FM, Valle D, Krieger I. Gyrate atrophy of the choroid and retina. Early findings. Ophthalmology 1985; 92: 395-401.

5 Kaiser-Kupfer MI, Valle DL. Clinical, biochemical, and therapeutic aspects of gyrate atrophy. Prog Retinal Res 1987 6: 179-206.

6 Takki K, Simell O. Gyrata atrophy of the choroid and retina with hyperornithinemia (HOGA). Birth Defects 1976; 12: 373-84.

7 Kuwabara T, Ishikawa Y, Kaiser-Kupfer MI. Experimental model of gyrate atrophy in animals. Ophthalmology 1981; 88: $331-4$.

8 Carlson S, Raitta C, Kommonen B. A d.c. electroretinography method for the recording of a-, b-, and c-waves. $\mathcal{F}$ Neurosci Methods. (In press)

9 Noell $W$. The origin of the electroretinogram. Am $\mathcal{F}$ Ophthalmol 1954; 38: 78-9.

10 Steinberg R, Schmidt R, Brown K. Intracellular responses to light from cat pigment epithelium: origin of the electroretinogram c-wave. Nature 1970; 227: 728-30.

11 Vannas-Sulonen K. Gyrata atrophy of the choroid and retina. MD thesis, University of Helsinki. ISBN 952-90013-4-7, Helsinki, 1988.

12 Ikeda H. Retinal mechanisms and the clinical electroretinogram. In: Haliday AM, Butler SR, Paul R, eds. A textbook of gram. In: Haliday AM, Butler SR, Paul R, eds. A textbook
clinical neurophysiology. New York: Wiley, 1987: 569-94.

13 Niemeyer G. Informazion von Der Netzhaut durch Electroretinografie. Graefes Arch Clin Exp Ophthalmol 1979; 211. 129-37.

14 Sieving P, Fishman G, Maggiano J. Corneal wick electrode for recording bright flash electroretinograms and early recepto potentials. Arch Ophthalmol 1978; 96: 899-900.

15 Gouras P. Electroretinography: some basic principles. Invest Ophthalmol Vis Sci 1970; 9: 557-69.

16 Takki K. Gyrata atrophy of the choroid and retina associated with hyperornithinaemia Brf Ophthalmol 1974 ; 58:3-23.

17 Berson EL, Schmidt SY, Rabin AR. Plasma amino-acids in hereditary retinal disease; ornithine lysine and taurine. $\mathrm{Br} \mathcal{F}$ Ophthalmol 1976; 60: 142-7.

18 Berson EL, Schmidt SY, Shih VE. Ocular and biochemical abnormalities in gyrate atrophy of the choroid and retina Ophthalmology 1978; 85: 1018-27.

19 Rinaldi E, Stoppoloni GP, Savastano S, Russo S, Cotticelli L. Gyrate atrophy of choroid associated with hyperornithinemia: report of the first case in Italy. $\mathcal{F}$ Pediatr Ophthalmol Strabismus 1979; 16: 133-5.

20 Hayasaka S, Saito T, Nakajima H, et al. Gyrate atrophy with hyperornithinemia: different types of responsiveness to vitamin B6. Br f Ophthalmol 1981; 65: 478-83.

21 Kaiser-Kupfer MI, Kuwabara T, Askanas V, et al. Systemic manifestations of gyrate atrophy of the choroid and retina. manifestations of gyrate atrophy

22 Brown K, Wiesel T. Localization of origins of electroretinogram components by intraretinal recording in the intact cat eye. F Physiol (Lond) 1961; 158: 257-80.

23 Oakley B, Green D. Correlation of light induced changes in retinal extracellular potassium concentration with the c-wave of the electroretinogram. F Neurophysiol 1976; 39 : 1117-33.

24 Boulton M, Marshall J. A mechanistic approach to the inherited retinal dystrophies and the role of tissue culture as an investigative probe. In: Sheffield JB, Hilfer SR, eds. Cell and developmental biology of the eye. Heredity and visual development. New York: Springer, 1985: 115-70. 